Joyful Learning Journal

\title{
PENGEMBANGAN MEDIA DIORAMA 3 DIMENSI DALAM PEMBELAJARAN IPA MATERI EKOSISTEM KELAS V
}

\section{Dady Mukti Prabowo ${ }^{\bowtie}$ Desi Wulandari}

Jurusan Pendidikan Guru Sekolah Dasar, Fakultas Ilmu Pendidikan, Universitas Negeri Semarang, Indonesia

\begin{tabular}{l} 
Info Artikel \\
\hline Sejarah Artikel: \\
Diterima Oktober 2017 \\
Disetujui November \\
2017 Dipublikasikan \\
Desember 2017
\end{tabular}

Keywords:

Diorama Media; 3

Dimension, Sains Education

\begin{abstract}
Abstrak
IPA merupakan salah satu mata pelajaran yang wajib diberikan kepada siswa SD, namun kenyataan dilapangan, pembelajaran IPA masih belum optimal. Berdasarkan data observasi, wawancara dan dokumentasi yang didapatkan di SDN Kalibanteng Kidul 02 Semarang ditemukan informasi bahwa terdapat permasalahan kurang tersedianya media yang relevan. Sehingga perlu dikembangkan media diorama 3 dimensi dalam pembelajaran IPA. Tujuan penelitian ini adalah untuk mendeskripsikan langkah-lanhak pengembangan media diorama 3 dimensi, untuk mengkaji kevalidan media diorama 3 dimensi, dan untuk mengkaji keefektifan media diorama 3 dimensi dalam pembelajaran. Jenis penelitian ini adalah Research and Development (R\&D) dengan langkah pra research, pengumpulan data, perancangan desain media, validasi produk, revisi produk, uji skala kecil, uji skala besar, dan produk akhir. Populasi penelitian ini adalah seluruh siswa kelas V SDN Kalibanteng Kidul 02 Semarang dan yang menjadi sampel adalah siswa kelas $\mathrm{V}$ dengan teknik sampel jenuh. Teknik pengumpulan data menggunakan observasi, wawancara, tes, angket, dan dokumentasi. Teknik analisis data menggunakan analisis data produk, analisis data awal/uji normalitas, uji t, uji N-Gain. Hasil penelitian menunjukan bahwa media diorama 3 dimensi layak digunakan dengan persentase penilaian validasi ahli media $94 \%$, ahli materi $97 \%$, praktisi media $97 \%$, dan praktisi materi $93 \%$ dengan uji T mendapat hasil

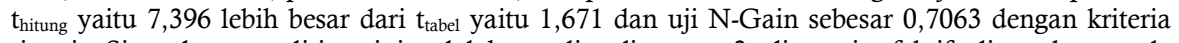
tinggi. Simpulan penelitian ini adalah media diorama 3 dimensi efektif digunakan pada pembelajaran IPA terhadap hasil belajar siswa. Saran penelitian selanjutnya dapat menerapkan media diorama 3 dimensi pada pembelajaran lain dengan menyesuaikan komponen dan desain sesuai materi yang diajarkan.
\end{abstract}

\begin{abstract}
Sains education is the one of lesson that must be given for student of elementary school, but in fact, Sains education still unoptimally done. Based on datas of observation, interview, and document that be found at Kalibanteng Kidul 02 Semarang State Elementary School is showed information that there is problem with the relevance learning media is still low. So, need to be developed 3 dimension diorama media in sains education. The purpose of this research is to describe the steps of developing 3 dimesion diorama media, to know about validity of 3 dimension diorama media, and to know about efectivity of 3 dimension diorama media in the learning. Type rsearch is Research and Development (R\&D) with some step are pra research, collecting data, preparing the media design, product validation, product reparation, small scale test, big scale test, and the last product. Research population is all student of grade $\mathrm{V}$ at Kalibanteng Kidul 02 Semarang State Elementary School. Research sample is student $\mathrm{f}$ grade V with jenuh sample technic. Collecting datas technic are observation, interview, test, angket, and documentation. Analyzing data technic use analyzing product data, analyzing first data/normality test, T test, and $\mathrm{N}-\mathrm{Gain}$ test. The result of the research shows that 3 dimension diorama media can be used in sains educational learning with the value percentage from media specialist is $94 \%$, content specialist is $97 \%$, media practicy is $97 \%$, and content practicy is $93 \%$ with Ttest result is T-assesment $(7,396)$ is bigger than T-table $(1,671)$ and N-Gain test result is 0,7063 with high criteria. This research conclusion is effectivally be used in sains educational learning toward student learning result. Instruction for the next research can use 3 dimension diorama media in other lesson by adapted with component and design is related with the content that be teach.
\end{abstract}

\footnotetext{
Alamat korespondensi: ISSN 2252-6366 Marongsari RT 06 RW 02, Sapuran, Wonosobo

E-mail: dady.mukti007@gmail.com
} 


\section{PENDAHULUAN}

Pendidikan memiliki peranan penting dalam perkembangan hidup manusia, untuk itu seseorang harus mendapatkan pendidikan yang tepat, dan pendidikan yang tepat adalah pendidikan yang berdasarkan Pancasila dan Undang-Undang Dasar Negara Republik Indonesia Tahun 1945. Sesuai dengan Undang-Undang Nomor 20 tahun 2003, fungsi Pendidikan Nasional adalah untuk mengembangkan kemampuan dan membentuk watak serta peradaban Bangsa yang bermartabat dalam rangka mencerdaskan kehidupan bangsa, bertujuan untuk mengembangkan potensi peserta didik agar menjadi manusia yang beriman dan bertakwa kepada Tuhan Yang Maha Esa, berakhlak mulia, sehat, berilmu, cakap, kreatif, mandiri, dan menjadi warga Negara yang demokratis serta bertanggung jawab.

Salah satu pelajaran yang wajib ditempuh oleh siswa adalah IPA, hal ini diperkuat dengan penjelasan yang disebutkan dalam Peraturan Menteri Pendidikan Nasional Nomor 22 Tahun 2006 tentang Standar Isi Satuan Pendidikan Dasar dan Menengah, disebutkan bahwa IPA merupakan salah satu mata pelajaran yang wajib diberikan mulai dari SD/MI/SDLB sampai SMP/MTs/SMPLB. Secara umum, tujuan pembelajaran IPA yang sudah dibuat tersebut sudah baik, namun kenyataannya di lapangan masih banyak sekali pelaksanaan pembelajaran IPA yang belum maksimal sehingga menyebabkan hasil belajar siswa masih rendah.

Berdasarkan hasil analisis PISA (Programme for International Student Assess-ment) tentang prestasi literasi membaca, matematika, dan sains siswa sekolah ber-usia 15 tahun yang dilakukan 3 tahun sekali didapatkan data rata-rata skor prestasi literasi sains. Berdasarkan data yang diperoleh, posisi Indonesia masih jauh dibawah rata-rata Internasional. Posisi siswa Indonesia pada tahun
2003 berada diperingkat ke-38 dari 40 Negara, pada tahun 2006 berada pada peringkat 50 dari 57 Negara, pada tahun 2009 ada diperingkat 60 dari 65 Negara dan pada tahun 2012 berada diperingkat 64 dari 65 Negara. Dan pada tahun 2015 berada diperingkat 62 dari 70 Negara yang berpartisipasi.

Berdasarkan hasil observasi dan wawancara yang telah dilakukan peneliti, pelaksanaan pembelajaran IPA di Kelas V SDN Kalibanteng Kidul 02 sudah sesuai dengan standar proses pendidikan, namun penggunaan medianya belum maksimal dan tidak relevan. Siswa sulit berkonsentrasi ketika pembelajaran sedang berlangsung. Siswa kurang antusias dan sering bermain sendiri didalam kelas. Hal ini menyebabkan hasil belajar IPA kurang maksimal. Berdasarkan data nilai dari guru kelas $\mathrm{V}$ tahun 2016/2017, nilai rata-rata IPA masih dibawah rata-rata mata pelajaran lain seperti IPS, Matematika, Bahasa Indonesia, dan PKn. Dari arsip dokumen nilai yang bersumber dari guru kelas V, mata pelajaran IPA memiliki rata-rata 75,19 ditunjukkan dengan data dari 36 siswa ada 14 siswa (39\%) yang mendapatkan nilai dibawah Kriteria Ketuntasan Minimal (KKM) yaitu 67, sedangkan sisanya 22 siswa (61\%) nilainya diatas KKM.

Berdasarkan masalah tersebut, diperlukan sebuah usaha agar dapat memperbaiki hasil belajar supaya menjadi lebih baik. Usaha yang tepat adalah dengan menggunakan media yang dapat menarik semangat, keaktifan dan perhatian siswa serta membuat siswa lebih antusias mengikuti pembelajaran. Media yang sesuai dengan pembelajaran IPA adalah media 3 dimensi. Media 3 dimensi yang dimaksud adalah diorama. Diorama dapat menjadi salah satu 
alterntif pemecahan masalah, karena diorama sangat sesuai dengan mata pelajaran IPA yang banyak membahas tentang fenomena-fenomena alam.

Pembelajaran dengan menggunakan media model 3 dimensi memberikan manfaat yang sangat besar. Sudjana (2015:206) menyatakan bahwa sebuah model memberikan impresi tiga dimensi dari objek nyata baik yang hidup maupun yang tidak. Oleh sebab itu model sangat membantu dalam mengkomunikasikan hakikat dari berbagai benda, baik yang terlalu besar, terlal kecil, terlalu jauh maupun dekat sehingga dapat dipahami oleh siswa.

Penelitian ini diperkuat oleh penelitian yang relevan yang pernah dilakukan oleh Kiswandari Septi (2016) dengan judul "Pengembangan Media Pembelajaran Diorama Daur Air pada Mata Pelajaran IPA Kelas V SD”. Hasil penelitian menunjukkan bahwa (1) validasi ahli media diperoleh rata-rata 3,88 dengan kategori baik. (2) validasi ahli materi diperoleh rata-rata 4,21 dengan kategori sangat baik. (3) penilaian praktisi diperoleh rata-rata 4,69 dengan kategori sangat baik. (4) hasil uji coba mendapat rata-rata 4,17 dengan kategori sangat baik. (5) hasil uji coba lapangan mendapat rata-rata 4,32 dengan kategori sangat baik.

Penelitian yang dilakukan oleh Enti ${ }^{1}$, M., Brako-Hiappa $^{1}$, G., Adu-Agyem ${ }^{1}$, J., Osei-Poku ${ }^{1}$, P., Steiner2, R. (2010) dengan judul "Diorama Art - A Potential Medium For Museum Education" hasil penelitian menunjukkan bahwa diorama sebagai media yang efektif untuk museum pendidikan. Selain itu, diorama bisa menjadi sebuah mini museum, alat ampuh untuk menyimpan catatan yang tepat, mendokumentasikan informasi budaya dan sejarah yang berharga untuk menginspirasi dan mendidik masyarakat, sertacara membangun museum di sekolah-sekolahu ntuk memperluas sumber belajar mengajar di kelas. Penelitian ini dirancang untuk membimbing semua orang agar tertarik dalam pembuatan diorama untuk memperoleh keterampilansendiri.Dari analisis inidapat disimpulkan bahwa diorama bisa berfungsi sebagai media alternatif untuk memperluas lingkup pendidikan museum di Negara.

Penelitian yang dilakukan oleh Rule, Audrey, C., Lindel, Lois, A. (2009) dengan judul "Making Cereal Box Diorama of Native American Historic Homes and Cuiltura" hasil penelitian menunjukkan bahwa Penelitin ini mengenai pembuatan diorama dalam kegiatan pembelajaran. Menurut penelitian ini pembuatan diorama tiga dimensi adalah yang paling berkesan dari pengalaman sekolah dasar, namun pada umumnya mereka jarang untuk melakukan kegiatan ini karena takut. Oleh karena itu, penting untuk mempersiapkan guru dengan keterampilan untuk memimpin anak-anak dalam menciptakan suatu proyek. Delapan puluh guru preservice terdaftar dalam kursus studi pembuatan diorama. Diorama tersebut bertema kelompok penduduk asli Amerika yang dibuat guru dari bahan kotak sereal, daur ulang kertas fotokopi, lem kerajinan putih, cat, gambar, dan barang-barang kerajinan umum.

Hasil penelitian sebelumnya menunjukkan bahwa media diorama sangat layak digunakan dalam pembelajaran, dan terbukti dapat membuat pembelajaran menjadi lebih baik. Berdasar referensi penelitian diatas, peneliti melakukan

penelitian pengembangan dengan mengembangkan media diorama.

Berdasarkan latar belakang tersebut, peneliti melakukan penelitian pengembangan dengan judul Pengembangan Media Diorama 3 Dimensi dalam Pembelajaran IPA Materi Ekosisem Kelas V SDN Kalibanteng Kidul 02 Semarang. 


\section{METODE PENELITIAN}

Desain peneltian pengembangan yang digunakan dalam penelitian ini adalahdesain/model Borg and Gall dalam Sugiono (2015:409). Langkah-langkah dalam desain pengembangan ini terdiri daari 10 langkah, yaitu; (1) potensi dan masalah; (2) pengumpulan data; (3) desain produk; (4) validasi desain; (5) revisi desain; (6) uji coba produk; (7) revisi produk (8) uji coba pemakaian; (9) revisi produk; (10) produksi akhir. Sumber data dan subjek penelitian yang dikaji yaitu siswa guru, ahli/pakar, lokasi, waktu, variabel, populasi dan sampel penelitian. Teknik pengumpulan data yang dipakai diantaranya observasi, wawancara, tes, angket, dan dokumentasi. Instrumen yang digunakan pada penelitian ini ada empat yaitu instrumen validasi ahli media, instrumen validasi ahli materi, instrumen validasi praktisi media, dan instrumen validasi praktisi materi.

Pengujian yang pertama dilakukan adalah uji coba soal, dan kemudian nilai hasil uji coba tersebut diolah datanya dengan menggunakan uji validitas, uji reliabilitas, uji taraf kesukaran, dan uji daya pembeda soal. Soal dikatakan valid jika rhitung $>$ rtabel, maka instrumen dikatakan valid. Soal dikatakan reliabel jika rhitung $>$ rabel maka instrumen dikatakan reliabel. Besarnya indeks kesukaran antara 0,00 sampai dengan 1,0. Daya pembeda soal adalah kemampuan soal untuk membedakan antara siswa yang berkemampuan tinggi dengan siswa yang berkemampuan rendah. Berdasarkan hasil perhitungan diatas, didapatkan 21 soal yang memenuhi keempat pengujian soal diatas. 21 soal tersebut kemudian digunakan sebagai soal pretest dan posttest.

Pengujian selanjutnya adalah penilaian validasi ahli dan praktisi. Instrumen yang digunakan untuk penilaian validasi adalah validasi ahli media, ahli materi, praktisi media, dan praktisi materi. Nilai hasil validasi tersebut kemudian dihitung menggunakan rumus percentage correction, dan setelah diperoleh persentasenya, kemudian dikonversikan ke kriteria penilaian validasi ahli dan praktisi. Media diorama 3 dimensi sudah selesai divalidasi, kemudian kelangkah selanjutnya yaitu uji skala kecil dan uji skala besar. Uji skala kecil dilakukan untuk mengetahui pendapat siswa tentang media diorama 3 dimensi. Instrumen yang digunakan adalah angket tanggapan siswa. Uji selanjutnya adalah uji skala besar, yang diakukan dengan cara melakukan tes sebelum pembelajaran dan tes setelah pembelajaran, guru siswa mengisi angket tanggapan mengenai diorama 3 dimensi setelah sesesai mengerjakan soal posttest. Hasil pretest dan posttest pada uji skala besar kemudian diuji pada analisis data awal dengan menguji normalitasnya menggunakan rumus chi kuadrat untuk mengetahui statistik apa yang akan digunakan selanjutnya. Berdasarkan hasil uji normalitas, dapat disimpulkan bahwa data tersebut normal dan ststitik selanjutnya yang digunakan adalah statistika parametrik. Dan uji yang dilakukan selanjutnya adalah uji $t$ dan N- Gain. Uji t digunakan untuk membandingkan hasil belajar sebelum dan sesudah treatment dapat diuji dengan menggunakan uji satu pihak. Untuk menguji peningkatan rata-rata (gain) yang akan menunjukkan ada tidaknya peningkatan hasil belajar setelah menggunakan media diorama 3 dimensi.

\section{HASIL PENELITIAN DAN PEMBAHASAN}

Langkah awal pembuatan media diorama 3 dimensi adalah dengan membuat rancangan media diorama 3 dimensi, kemudian membuat media awal atau desain. Desain kemudian diuji validasinya oleh ahli media, materi, praktisi media, dan praktisi materi. Berikut 
ini disajikan tabel hasil penilaian vaidasi ahli dan praktisi:

Tabel 1. Rekapitulasi Hasil Perhitungan Instrumen Validasi Ahli Media, Ahli Materi, Praktisi Media, dan Praktisi Materi

\begin{tabular}{|c|c|c|c|c|c|}
\hline \multirow[t]{2}{*}{ No } & \multirow{2}{*}{$\begin{array}{l}\text { Nama } \\
\text { instrumen }\end{array}$} & \multirow[t]{2}{*}{ Skor } & Skor & Hasil & \multirow{2}{*}{ Kriteria } \\
\hline & & & Maksimal & Persentase & \\
\hline & Validasi & & & & \\
\hline & Ahli & & & & Sangat \\
\hline 1 & $\begin{array}{l}\text { Media } \\
\text { Validasi }\end{array}$ & 30 & 32 & $94 \%$ & Layak \\
\hline 2 & $\begin{array}{l}\text { Ahli } \\
\text { Materi } \\
\text { Validasi }\end{array}$ & 31 & 32 & $97 \%$ & $\begin{array}{l}\text { Sangat } \\
\text { Layak }\end{array}$ \\
\hline 3 & $\begin{array}{l}\text { Praktisi } \\
\text { Media } \\
\text { Validasi }\end{array}$ & 31 & 32 & $97 \%$ & $\begin{array}{l}\text { Sangat } \\
\text { Layak }\end{array}$ \\
\hline 4 & $\begin{array}{l}\text { Praktisi } \\
\text { Materi }\end{array}$ & 26 & 28 & $93 \%$ & $\begin{array}{l}\text { Sangat } \\
\text { Layak }\end{array}$ \\
\hline
\end{tabular}

Langkah berikutnya adalah memperbaiki media diorama 3 dimensi agar menjadi lebih baik, sesui dengan saran dari ahli dan praktisi.

Berdasarkan hasil uji normaitas ini didapat hasil bahwa nilai pretest dan posttest berdistribusi normal karena $\mathrm{X}^{2}$ hitung $<\mathrm{X}^{2}$ tabel. Karena data berdistribusi noral maka statistik yang digunakan selanjutnya adalah $\mathrm{T}$ tes dan $\mathrm{N}$ Gain. Uji $\mathrm{t}$ digunakan untuk membandingkan hasil belajar sebelum dan sesudah menggunakan media diorama 3 dimensi uji $t$ dihitung dan kemudian hasilnya dibandingkan dengan Ttabel. Karena $T_{\text {hitung }}>\mathrm{T}_{\text {tabel, }}$ maka dapat disimpulkan bahwa media diorama 3 dimensi layan digunakan pada pembelajaran IPA materi ekosistem. Beriktu ini hasil perhitungan uji t:

Tabel 2. Uji T Nilai Pretest dan Posttest

\begin{tabular}{cccccc}
\hline Data & Thitung & Alpha dk & Ttabel & Kriteria \\
\hline Pretest & & & & & \\
& 7,396 & $5 \%$ & 58 & 1,671 & Ha diterima \\
Pottest & & & & &
\end{tabular}

Uji N-gain digunakan untuk menguji peningkatan rata-rata (gain) yang akan Menunjukkan ada tidaknya peningkatan hasil belajar setelah menggunakan media diorama 3 dimensi. Perhitungannya menggunakan rumus N-Gain. Hasil perhitungan N-Gain disajikan pada tabel berikut:

Tabel 3. Hasil Perhitungan N-Gain

\begin{tabular}{cc}
\hline Kategori & Nilai \\
\hline Rata-rata Pretest & 55.17 \\
Rata-rata Posttest & 86.83 \\
Selisih rata-rata & 31.67 \\
Nilai Gain & 0.7063 \\
Kriteria & Tinggi \\
\hline
\end{tabular}

Berdasarkan tabel 3, diketahui bahwa peningkatan gain nilai pretest dan posttest sebesar 0.7063 termasuk dalam kriteria tinggi dengan selisih rata-rata 31.67.

Berdasarkan analisis data akhir dengan perhitungan T-tes dan N-gain dapat disimpulkan bahwa media diorama 3 dimensi layak digunakan pada pembelajaran IPA dan peningkatan nilaipretest dan posttest sebesar 0,763 dan termasuk dalam kriteria tinggi.

Penelitian yang mendukung adalah penelitian yang dilakukan oleh Robbayani Annisa (2016) dengan judul “ Pengembangan Media Diorama pada Mata Pelajaran Geografi Materi Perairan Laut terhadap Hasil Belajar Siswa Kelas X IIS di MAN Tempursari Ngawi Tahun Ajaran 2015/2016". Hasil penelitian menunjukkan bahwa : (1) validasi ahli media diperoleh presentasenya 90\% dan masuk kriteria sangat layak. (2) validasi oleh ahli materi diperoleh presentase $94,28 \%$ dan termasuk dalam kategori sangat layak. (3) hasil pengamatan aktifitas guru berpresentase $86,66 \%$ dan masuk kategori sangat baik. (4) hasil angket respon siswa mendapat presentase 96,09\% dan termasuk kategori sangat baik.

Penelitian yang dilakukan oleh Robbayani Annisa (2016) dengan judul “ Pengembangan Media Diorama pada Mata Pelajaran Geografi Materi Perairan Laut 
terhadap Hasil Belajar Siswa Kelas X IIS di MAN Tempursari Ngawi Tahun Ajaran 2015/2016". Hasil penelitian menunjukkan bahwa : (1) validasi ahli media diperoleh presentasenya $90 \%$ dan masuk kriteria sangat layak. (2) validasi oleh ahli materi diperoleh presentase $94,28 \%$ dan termasuk dalam kategori sangat layak. (3) hasil pengamatan aktifitas guru berpresentase $86,66 \%$ dan masuk kategori sangat baik. (4) hasil angket respon siswa mendapat presentase $96,09 \%$ dan termasuk kategori sangat baik.

Media diorama 3 dimensi merupakan media yang kongkret dan memberikan pengalaman langsung kepada siswa dalam mempelajari ekosistem. Hal ini sesuai dengan landasan teori penggunaan media yaitu kerucut pengalaman Dale (Dale's Cone of Experience). berdasarkan kerucut pengalaman Edgar Dale tersebut dijelaskan bahwa media yang paling baik adalah melalui pengalaman langsung. Media diorama 3 dimensi memberikan pengalaman langsung kepada siswa melalui pengamatan pada diorama ini. Siswa juga aktif dalam pembelajaran dengan mengumpulkan data mengenai hal-hal yang ada pada diorama kemudian menyimpulkannya. Media diorama 3 dimensi berbentuk kongkret, sehigga memudahkan siswa dalam belajar, hal ini sesuai dengan teori perkembangan kognitif menurut Piaget, yang menyatakan bahwa anak usia SD berada pada tahap operasional kongkret yang tipe belajarnya menggunakan benda kongkret.

Penelitian yang dilakukan Darajati Pintanti (2016) dengan judul "Pengembangan Media Diorama Lingkungan (Dolan) sebagai Media Pembelajaran IPS Kelas III SDN Tahunan" hasil penelitian ini menunjukkan bahwa : (1) hasil akhir validasi materi memperoleh rerata skor 4,47 dengan kriteria "sangat baik". (2) hasil akhir validasi media memperoleh skor 4,1 dengan kriteria "sangat baik". (3) hasil penilaian praktisi memperoleh skor 4,1 dengan kriteria "sangat baik". (4) hasil uji lapangan memperoleh skor rata-rata 4,2 dengan kriteria "sangat baik". Media diorama membuat siswa aktif dalam pembelajaran. Siswa melakukan kegiatan pengamatan pada diorama 3 dimensi yang kemudian hasil pengamatan itu dicatat, dikelompokkan dan disimpulkan, sehingga pembelajaran menjadi lebih bermakna bagi siswa. Kegiatan pembelajaran IPA dengan menggunakan media diorama 3 dimensi membuat siswa melakukan kegiatan pengamatan, mencatat hasil pengamatan, mengelompokkan dan menyimpulkan, kegiatan ini merupakan keterampilan proses IPA yang dilakukan siswa. Funk (1985) dalam Dimyati (2002:140) menjelaskan bahwa keterampilan proses dapat diklasifikasikan menjadi dua yaitu keterampilan proses dasar (basic skill) dan keterampilan terintegrasi (integrated skill), dan melalui media diorama 3 dimensi ini dapat mengasah keterampilan proses IPA siswa.

Pembelajaran IPA dengan menggunakan media diorama 3 dimensi juga mengandung empat hakikat IPA. Menurut Carin and Sund (1993) dalam Wisudawati (2015:24) hakikat IPA ada empat yaitu IPA sebagai proses, IPA sebagai sikap, IPA sebagai produk, dan IPA sebagai aplikasi. IPA sebagai sikap dalam penelitian ini diwujudkan dalam sikap ilmiah yang dimiliki siswa seperti sikap ingin tahu, teliti, disiplin dan tidak putus asa. Sikap-sikap ini timbul saat siswa mendapat produk IPA melalui proses mengamati dan mengobservasi media diorama ini.IPA sabagai proses dalam penelitian ini adalah dengan siswa memperoleh pengetahuan IPA tentang ekosistem yaitu dengan cara mengamati dan mengobservasi dan yang ada pada media diorama 3 dimensi ini. Kemudian mengelompokkan benda abiotik dan biotik berdasarkan media diorama ekosistem yang 
disajikan. Dengan melakukan kegiatan tersebut maka siswa akan lebih mudah memahami materi yang diajarkan. IPA sebagai produk dalam penelitian ini adalah materi berupa fakta, konsep dan teori tentang ekosistem. Contohnya yaitu fakta bahwa dalam suatu ekosistem terdiri dari beberapa komponen makhluk hidup dan konsep tentang benda biotik dan abiotik yang ada pada suatu ekosistem. IPA sebagai aplikasi dalam penelitian ini disesuaikan dengan materi yaitu ekosistem. Aplikasinya yaitu untuk menjaga ekosistem dan lingkungan yang ada agar terhindar dari bencana dan kerusakan. Khususnya adalah global warming yang saat ini mulai terasa efeknya. Usaha yang bisa dilakukan untuk menjaga ekosistem adalah dengan melakukan reboisasi, dan tidak membuang sampah disembarang tempat.

Keefektifan media diorama 3 dimensi ini dapat diketahui melalui T-tes dan peningkatan hasil belajar siswa. Berdasarkan landasan teori penggunaan media dalam kerucut pengalaman Edgar Dale dalam Arsyad (2014:14), menyatakan bahwa pengalaman langsung membuat siswa lebih mudah memahami hal yang ia pelajari, karena siswa mengalami langsung pembelajaran dengan pengalaman langsung tesebut dan pembelajaran menjadi sangat bermakna bagi siswa. Pembelajaran dengan menggunakan media diorama 3 dimensi memberikan pengalaman langsung kepada siswa untuk mengamati sebuah ekosistem, sehingga siswa menjadi lebih memahami materi yang dipelajari. Sesuai dengan teori perkembangan kognitif Piaget, siswa SD berada pada tahap operasional kongkret dan belajar melalui benda-benda yang kongkret atau nyata. Melalui media diorama 3 dimensi, siswa secara nyata mengamati ekosistem hutan, sehingga siswa menjadi lebih paham dengan materi yang diajarkan dan hasil belajar siswa juga meningkat.

Penelitian yang mendukung adalah penelitian yang dilakukan oleh Lestari Tri (2015) dengan judul "Pengaruh Penggunaan Media Diorama terhadap Hasil Belajar Siswa Kelas V pada
Tema Ekosistem di Sekolah Dasar " Berdasarkan hasil penelitian yang telah dilakukan di SDN Ketintang I Surabaya dapat disimpulkan bahwa penggunaan media diorama pada tema ekosistem mempunyai pengaruh yang signifikan terhadap hasil belajar siswa sehingga hipotesis yang telah dirumuskan berbunyi ha dapat diterima dan ho ditolak. Hal ini dibuktikan dengan hasil:Hasil uji-t dengan menggunakan taraf signifikan $5 \%, \mathrm{db}=68$ diperoleh thitung 2,678, jika dibandingkan dengan harga tabel 1,667, maka thitung lebih besar dari tabel $(2,678>1,667)$. Sehingga terdapat perbedaan yang signifikan hasil belajar kelompok eksperimen yang menggunakan media diorama dengan kelompok kontrol yang tidak menggunakan media diorama. Dari hasil tersebut dapat disimpulkan bahwa penggunaan media diorama berpengaruh signifikan terhadap hasil belajar siswa pada tema ekosistem.

Penelitian yang dilakukan oleh Marandino,Martha., Oliveira,Adriano, Dias., Mortensen, Marianne (2009) dengan judul "The Important Role Of Natural History Dioramas In Biological Learning" hasil penelitian menunjukkan bahwa Penelitian dan evaluasi program penggunaan diorama di museum secara empiris dan statistik menunjukkan bahwa program telah memenuhi tujuan yang telah ditetapkan. Data Kualitatif juga mendukung bahwa tujuan dan sasaran telah terpenuhi, diantaranya: (1) pengunjung menemukan tokoh yang unik, menarik, pendidikan, menyenangkan, dan mudah diingat; (2) pameran dalam ruang museum dianggap lebih kuat, unik, dan pribadi atau bermakna oleh pengunjung yang berinteraksi dengan tokoh. Dengan diorama mereka tidak hanya 
ingat substansi sebenarnya namun juga keakuratan.

\section{SIMPULAN}

Berdasarkan hasil penelitian dan pembahasan, dapat diambil kesimpulan sebagai berikut, Pengembanagan media diorama ini menggunakan desain pengembangan Borg \& Gall menurut Sugiono. Langkah penelitian yang sudah dilaksanakan dalam penelitian ini adalah: pra research, pengumpulan data, perancangan desain media, validasi produk, revisi produk, uji skala kecil, uji skala besar, dan produk akhir; Media diorama 3 dimensi yang telah dikembangkan dinyatakan layak digunakan oleh ahli media, ahli materi, praktisi media, dan praktisi materi; Media diorama 3 dimensi efektif digunakan pada pembelajaran IPA terhadap hasil belajar siswa dengan perhitungan thitung lebih besar dari tabel dengan uji N-Gain sebesar 0,7063 dengan kriteria tinggi.

\section{UCAPAN TERIMAKASIH}

Peneliti mengucapkan terimakaish kepada kedua orang tua yang selalu memberikan dukungan moral, spiritual, dan material kepada peneliti. Dosen pembimbing utama Desi Wulandari, S.Pd, M.Pd, dosen pembimbing pendamping Dra. Sri Hartati, M.Pd, yang telah memberikan bimbingan dan koreksi pada artikel ini.

\section{DAFTAR PUSTAKA}

Arsyad, Azhar. 2014. Media Pembelajaran.

Jakarta: Rajawali Press.

Darajati, Pintanti. 2016. "Pengembangan media diorama lingkungan (dolan) sebagai media pembelajaran IPS kelas III SDN Tahunan". Jurnal Pendidikan Guru Sekolah Dasar, 5(4): 296-303.
Dimyati dan Mudjiono. 2002. Belajar Dan Pembelajaran. Jakarta: Rineka Cipta.

Enti $^{1}$, M., Brako-Hiappa ${ }^{1}$, G., Adu-Agyem ${ }^{1}$, J., Osei-Poku' ${ }^{1}$, P., Steiner2, R. 2010. "Diorama Art - A Potential Medium For Museum Education". Journal of science and Technology, 30(2): 76-85.

Kiswandari, Septi. 2016. "Pengembangan Media Pembelajaran Diorama Daur Air pada Mata Pelajaran IPA Kelas V SD". Jurnal Sekolah Dasar, Pendidikan Guru 5(10): 970-975.

Lestari, Tri. 2015. "Pengaruh Penggunaan Media Diorama terhadap Hasil Belajar Siswa Kelas V pada Tema Ekosistem di Sekolah Dasar ".

JPGSD, 03(02): 1114-1123.

Marandino,Martha., Oliveira,Adriano,

Dias., Mortensen, Marianne.

2009."The Important Role Of

Naural

History Dioramas In

Biological Learning". ICOM

Natural History Committee Newsletter.

No 29: 1-41. ISSN 1814-6058.

Peraturan Menteri Pendidikan Nasional

No 22 Tahun 2006.

Prastowo, Andi. 2015. Panduan Kreatif

MembuatBahan AjarKreatif.

Jogjakarta: DIVA Press.

Robbayani, Annisa.

2016.

"Pengembangan Media Diorama pada Mata Pelajaran Geografi Materi Perairan Laut terhadap Hasil Belajar Siswa Kelas X IIS di MAN Tempursari Ngawi Tahun Ajaran 2015/2016". Jurnal Swara Bhumi, 01(02): 28-37. 
Rule, Audrey, C., Lindel, Lois, A. 2009. "Making Cereal Box Diorama of Native American Historic Homes and Cultural". : 1-63.

Sudjana, Nana., dan Rivai, Ahmad. 2015. Media Pengajaran. Bandung: Sinar Baru Aglesindo.
Sugiyono. 2015. Penelitian RnD. Bandung: Alfabeta.

Undang-undang Republik Indonesia Nomor 20 tahun 2003.

Wisudawati, Asih, Widi., Sulistyowati, Eka. 2015. Metodologi Pembelajaran IPA. Jakarta: Bumi Aks 
